\title{
Comparison of intraoral radiography and cone-beam computed tomography for the detection of periodontal defects: an in vitro study
}

\author{
Nilsun Bagis ${ }^{1 *}$, Mehmet Eray Kolsuz ${ }^{2 \dagger}$, Sebnem Kursun ${ }^{3 \dagger}$ and Kaan Orhan ${ }^{2+}$
}

\begin{abstract}
Background: This study aimed to compare the diagnostic accuracy of cone-beam computed tomography (CBCT) unit with digital intraoral radiography technique for detecting periodontal defects.

Methods: The study material comprised 12 dry skulls with maxilla and mandible. Artificial defects (dehiscence, tunnel, and fenestration) were created on anterior, premolar and molar teeth separately using burs. In total 14 dehiscences, 13 fenestrations, eight tunnel and 16 without periodontal defect were used in the study. These were randomly created on dry skulls. Each teeth with and without defects were images at various vertical angles using each of the following modalities: a Planmeca Promax Cone Beam CT and a Digora photostimulable phosphor plates. Specificity and sensitivity for assessing periodontal defects by each radiographic technique were calculated. Chi-square statistics were used to evaluate differences between modalities. Kappa statistics assessed the agreement between observers. Results were considered significant at $P<0.05$.
\end{abstract}

Results: The kappa values for inter-observer agreement between observers ranged between 0.78 and 0.96 for the $\mathrm{CBCT}$, and 0.43 and 0.72 of intraoral images. The Kappa values for detecting defects on anterior teeth was the least, following premolar and molar teeth both CBCT and intraoral imaging.

Conclusions: $C B C T$ has the highest sensitivity and diagnostic accuracy for detecting various periodontal defects among the radiographic modalities examined.

Keywords: CBCT, Periodontal defect, Intra-oral radiography, Fenestrations, Tunnel

\section{Background}

Current approaches to diagnose periodontal disease include probing of gingival tissues and radiographs to evaluate osseous support. Information derived from probing the gingival tissues in association with diagnostic imaging provides guidelines for assessing the alveolar bone height and checking for the presence of bone defects $[1,2]$.

Today, a number of intraoral and extra-oral imaging modalities are available to assist in the examination of the periodontal patient. Commonly used two-dimensional (2D) modalities include bitewing, periapical, and panoramic radiography. These modalities are suitable because they are easily acquired, cheap and provide high-resolution images.

\footnotetext{
* Correspondence: nilsunbagis@yahoo.com

${ }^{\dagger}$ Equal contributors

'Faculty of Dentistry, Department of Periodontology, Ankara University, 06560, Besevler, Ankara, Turkey

Full list of author information is available at the end of the article
}

Additionally, all of these modalities can provide important diagnostic information indeed, but none of them without limitations [3]. They are limited by overlapping anatomical structures $[4,5]$, difficulty in standardization [1-5], and by underestimating the size and occurrence of bone defects [6].

Studies indicated that intra-oral radiography underestimates the alveolar bone loss due to projection errors or observer errors [7-9]. There is sample research demonstrating that funnel-shaped or lingually located defects cannot be detected and that destruction of the buccal plate can be undiagnosed or undistinguished from lingual defects [5].

For this instance, three-dimensional (3D) modalities as a cone beam computed tomography (CBCT) images of periodontal bone started to use and offers a highly informative value [10]. The use of CBCT in clinical practice offers a 
number of potential advantages over conventional tomography, including easier image acquisition, high image accuracy, reduced artefacts, and lower effective radiation doses [11].

Research comparing the use of $3 \mathrm{D}$ and $2 \mathrm{D}$ images in artificial bone defects have shown that CBCT has a sensitivity of $80-100 \%$ in the detection and classification of bone defects, while intraoral radiographs present a sensitivity of 63-67\%, CBCT has also shown an absence of distortion and overlapping and the dimensions it presents are compatible with the actual size [12-14]. Although, CBCT has certain advantageous regarding 3D imaging over $2 \mathrm{D}$ radiographies, there are still observer dependent issues on the assessment of alveolar bone and periodontal defects. Examiner interpretation errors confound data analysis and cast doubt on the validity of results esp. while evaluating the observer agreement of alveolar bone loss.

There are so far limited studies on periodontal defects and alveolar bone loss on CBCT Imaging [4, 5, 10, 14-20]. Hence, it was considered to worthwhile to compare 2D intra-oral radiographs and 3D CBCT images on detection of different types periodontal bone defects in dry skulls using CBCT imaging.

\section{Methods}

Using retrospective data of the literature, a power analysis (Power and Precision software, Biostat, Englewood, NJ, USA) was conducted that indicated that detection of differences between 2D radiographs and 3D CBCT images could be obtained with at least 35 defects at a power of 0.8 (alpha $=0.05$ ). Thus, this study was conducted using 12 dry skulls with maxilla and mandible and 35 artificial defects (dehiscence, tunnel [furcation defect level III], and fenestration) which were created on incisors, premolars and molar teeth separately using burs.

The skulls were obtained from different museums in our country. All skulls were dated back $10^{\text {th }}$ Century from different parts of country which were approved to be used for scientific study that were given by City Culture and Tourism Authorities which are connected to Anadolu Civilization Museum.

In total 14 dehiscences, 13 fenestrations, eight tunnel and 16 without periodontal defect were used in the study. These were randomly created on dry skulls. For soft tissue simulation, maxilla and mandible were covered by double layers of boxing wax (Fig. 1). The defects were created by periodontal consultant (NB) in line with Mengel et al's study [21]. The consultant noted the periodontal defects and these were used as the Gold standard for radiographic evaluation. The periodontal defects were created using high-speed equipment with copious air/water spray and rounded diamond burs (KG Sorensen, Zenith Dental ApS, Agerskov, Denmark).

\section{Dehiscences}

Deshiscences were prepared in 5 molars, 4 premolars and 5 anterior teeth. The buccal bone in the coronal region of the teeth was removed until parallel walls until the walls are paralleled. The dehiscences had a standard dimension,

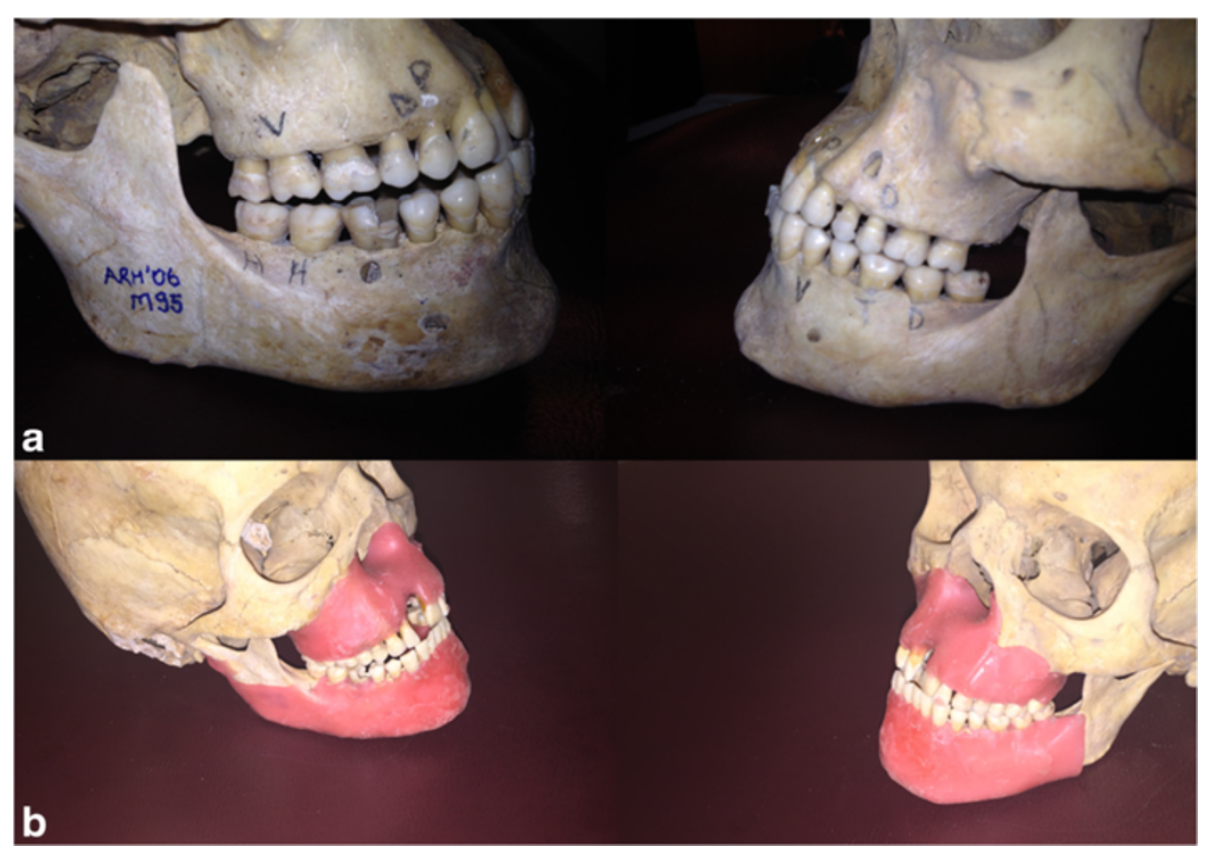

Fig. 1 The photograph of the skulls (a) with defects, (b) and with wax covered to simulate the soft tissue 
approximately $10 \mathrm{~mm}$ height and $3 \mathrm{~mm}$ width from enamelcement junction of the teeth (Fig. 2) 14.

\section{Fenestrations}

Fenestrations were prepared in 5 molars, 4 premolars, 4 anterior teeth both in maxilla and mandible. The buccal bone in the central thirds of the tooth was removed until the walls ere parallel. The fenestrations had a standard dimension, approximately $4 \mathrm{~mm}$ height and $3 \mathrm{~mm}$ width (Fig. 2).

\section{Tunnels}

All tunnel defects were prepared in mandibular molar teeth. The buccal bone lingual bone in the furcation region was removed until a continuous defect was produced. The lowest point of of the furcation was prepared as diameter of the bur, approximately $2 \mathrm{~mm}$ height from the furcation roof (Fig. 2).

\section{Radiographic imaging}

Each skull were exposed using a Planmeca Promax CBCT (Planmeca, Promax 3D max, Helsinki, Finland) and a Digora photostimulable phosphor plates (PSP). CBCT exposures were made in $96 \mathrm{kVp}$ and $12 \mathrm{~mA}$ at 0.100 $\mathrm{mm}^{3}$ voxel size. The field of view was $5 \mathrm{~cm}$ in diameter and 5, $5 \mathrm{~cm}$ in height. Slice were 1024x1024 pixels. Axial, sagittal, cross-sectional images were reconstructed for all skulls, and 3D reconstructions were used as necessary (Fig. 3).

In addition to the CBCT images, a set of digital intraoral standardized periapical images was obtained. The radiographs were obtained with an intra-oral X-ray system operating at $70 \mathrm{kVp}, 8 \mathrm{~mA}$ by Evolution $\times 3000-2 \mathrm{c}$ (Grugliasco, Italy) and a phosphor plate digital system (Digora Soredex, Soredex Medical Systems, Helsinki, Finland). Exposure time was $0.1 \mathrm{~s}$. These were taken using parallel technique with a XCP system (Rinn Co., IL, USA) device with a 12 in. cone attached. Standardization was achieved with bite blocks that were used in all radiographic examinations. The use of the paralleling technique, complemented with a positioning holder and bite blocks, minimized image enlargement and geometric distortion of the radiographs (Fig. 4).

\section{Image evaluation}

All digital intraoral images were saved in noncompressed file format (tagged image file format, TIFF). All images were displayed and evaluated on a 21.3-inch flat-panel color-active matrix thin-film transistor (TFT) medical display (NEC MultiSync MD215MG, Munchen, Germany) with a resolution of $2048 \times 2560$ at $75 \mathrm{~Hz}$ and $0.17-\mathrm{mm}$ dot pitch operated at 11.9 bits. Digital intraoral images were displayed using the dedicated software of Digora imaging system (Soredex Medical Systems, Helsinki, Finland) whereas CBCT images were evaluated with its own software (Romexis 3.2, Planmeca, Helsinki, Finland). Observation conditions were optimized through use of the same computer monitor when the images were displayed. Viewing distance was kept constant to about $50 \mathrm{~cm}$ for the observer, and the lights were subdued during examinations.

Two dental radiologists (MEK, SK), all with 3-5 years' experience of working with the $\mathrm{CBCT}$ technique examined the PSP, and CBCT images for the presence of periodontal defects in different sessions. The scores assigned by the observers were recorded by a researcher (KO) who knew the study design and had previously enhanced the images. The observers were aware that some teeth have no periodontal defects. All of the observers had access to the two views simultaneously for the intraoral and $\mathrm{CBCT}$ techniques. The time allocated for the observations was not restricted. Adjustment of contrast and brightness could be done, if considered necessary, using the inbuilt image display tools.

The observers were asked to define the type of the defects and also define the teeth without periodontal defects. In line with Braun's study [10], the defects were classified being present or absent or may have been uncertain while making the diagnosis (correct, false, or questionable). In addition, all of the images were evaluated by the same examiners. For this reason, the results, positive correct and negative-correct, were summarized as "correct." The answers: positive-false, positive-questionable, and negative-false and negative-questionable were considered "incorrect." The level of significance was accepted at $\mathrm{p}<0.05$.

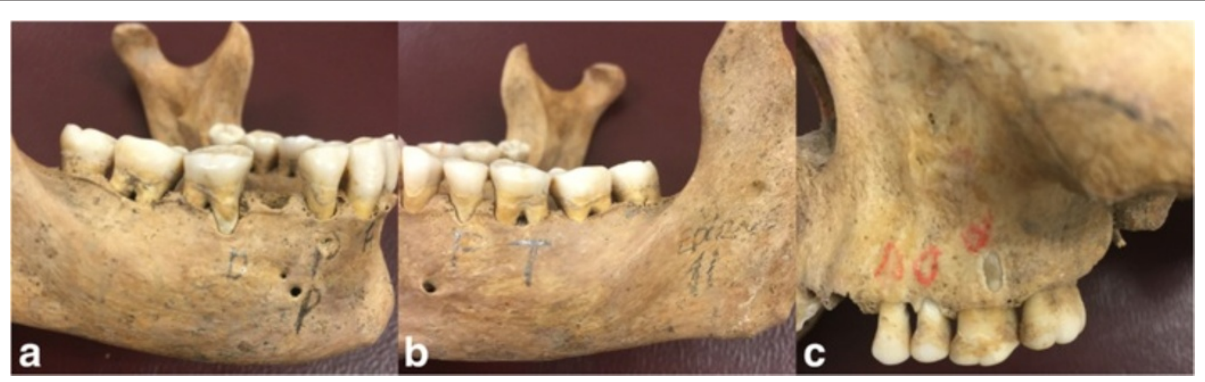

Fig. 2 The photograph of the defects, (a) dehiscences, (b) tunnel, and (c) fenestration 


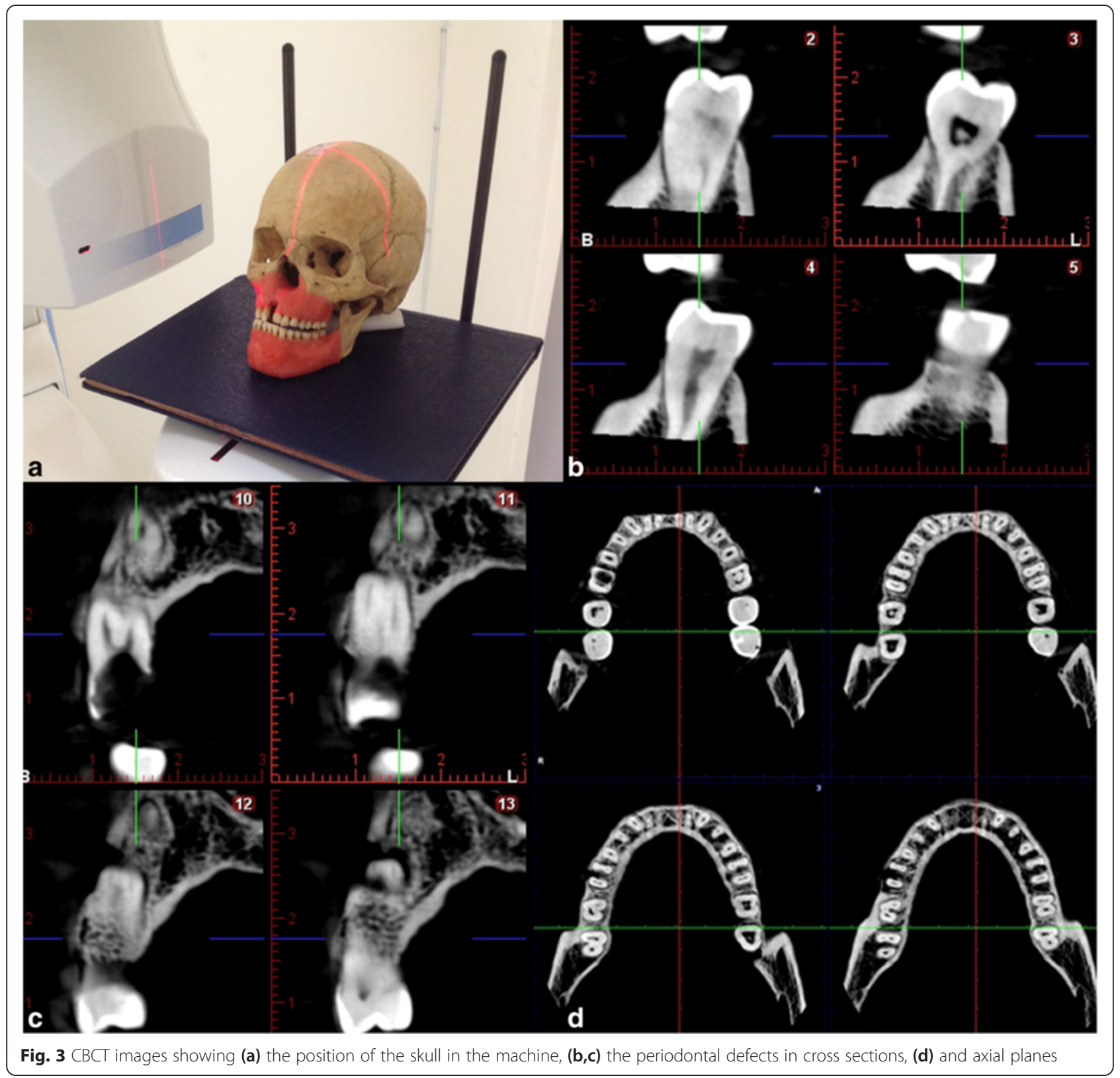

All observers inter and intra evaluations were compared according to Gold standard which were created and noted by the periodontal consultant. Specificity and sensitivity for each radiographic technique were calculated. Kappa statistics was used for assessing the agreement between observers using the NCSS 2007 statistical software (NCSS and GESS, NCSS, LLC. Kaysville, UT, USA). Kappa statistics were used to determine inter and intra-observer agreement. The kappa values were interpreted according to guidelines of Landis and Koch adapted by Altman [22]. $\mathrm{k} \leq 0.20$ Poor, $0.21-0.40$ Fair, 0.410.60 Moderate, $0.61-0.80$ Good, $0.81-1.00$ Very good. The determination of the significance level was done using the
McNemar test using paired samples. Results were considered significant at $\mathrm{p}<0.05$.

\section{Results}

Table 1 shows mean inter observer agreement for the radiographic modalities. CBCT showed a significantly greater value than the PSP. Significant difference was found between PSP and CBCT. The kappa values for inter-observer agreement between observers ranged between 0.78 and 0.96 for the CBCT, and 0.43 and 0.72 of intraoral images. The Kappa values for detecting defects on anterior teeth was least, following premolar and molar teeth both CBCT and intraoral imaging (Table 1). 


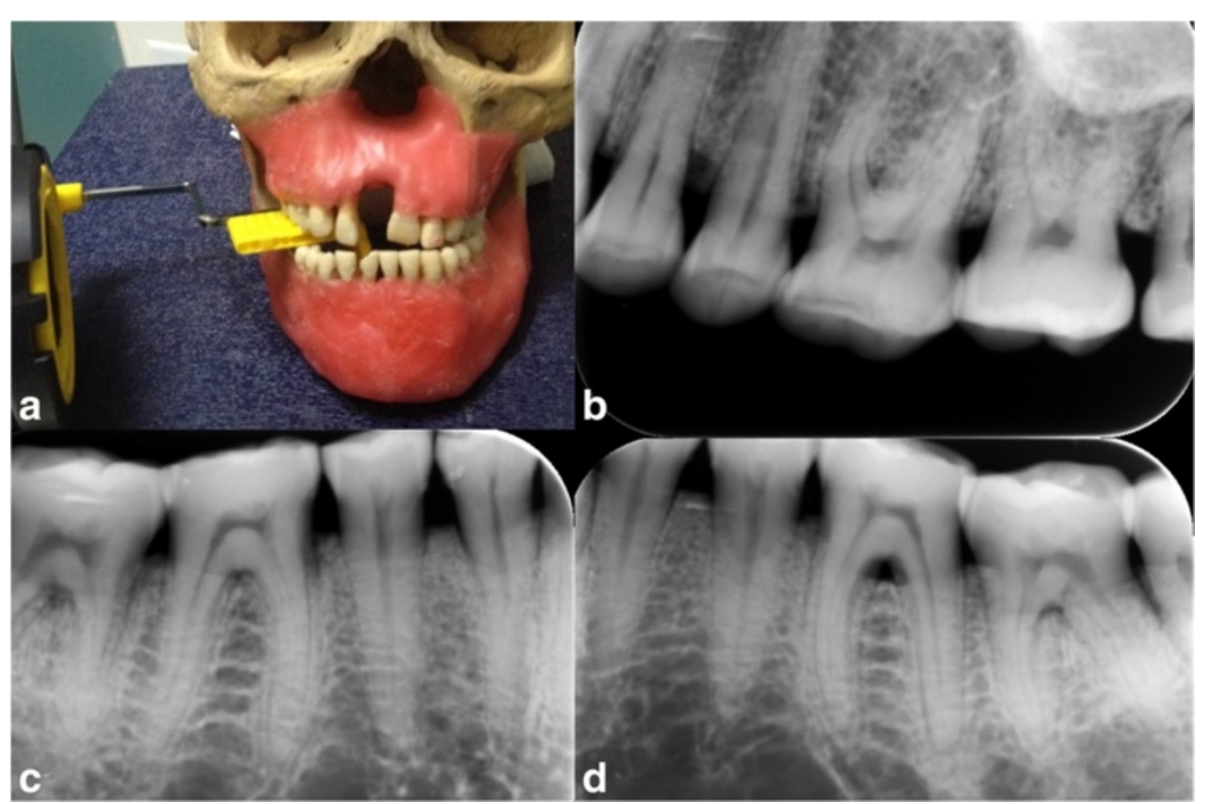

Fig. 4 PSP intra-oral imaging (a) the positioning of the exposure, $(\mathbf{b}, \mathbf{c}, \mathbf{d})$ the $2 \mathrm{D}$ images of the periodontal defect

Table 2 shows the Kappa values for intraoral digital sensor and the CBCT images assessed by the two observers. Considering the observer means, cone beam dental CT images revealed significantly higher sensitivities $(\mathrm{P}<0.05)$ than the intraoral systems between which no significant differences were found. The kappa values for intra-observer agreement between observers ranged between 0.42 and 0.816 for the intra-oral evaluations and 0.73 and 0.924 for the CBCT evaluations. The Kappa values for detecting defects on anterior teeth was least, following premolar and molar teeth both CBCT and intraoral imaging (Table 2).

Table 3 summarizes the survey results for defect types "dehiscence", "tunnel" and "fenestration." Bony dehiscence, the statistical analysis showed that CBCT statistically significant better results than the conventionally used twodimensional radiograph. Similarly CBCT again showed better performance on detecting the tunnel and fenestrations than $2 \mathrm{D}$ radiographs $(\mathrm{p}<0.05)$.

\section{Discussion}

Plain conventional radiography is the most commonly used method to aid in the diagnosis of periodontal defects because of its low cost, convenience, and high resolution. However, while evaluating the images, with conventional 2D image is hard to identify a 3D structure (defects), when interpreting these radiographs esp. periodontal defects a third dimension is crucial in order to identify the nature and the course of the defects [14-20]. The present study compared the diagnostic accuracy of CBCT scans and PSP in the detection of periodontal defects. Both intra-and inter-observer agreement values for CBCT were relatively better than PSP intra-oral radiographies. The highest kappa values were obtained with $\mathrm{CBCT}$ images of the molars, following premolar and the anterior teeth. Overall, CBCT $8 \times 8-\mathrm{cm}$ Field of view (FOV) was found to detect periodontal defects significantly better than PSP which are in-line with previous studies $[4,5,14-18,20,21,23,24]$.

Gomes-Filho et al. [23] compared the artificial induced periodontal defects with digital photographs and conventional radiographs by evaluation of three examiners. They classified the defects as; horizontal, vertical, interdental crater, one, two, three-wall infrabony defects, septum bone defect. In conclusion they stated that such diagnoses for different types of periodontal defects are extremely difficult to make. In line with our study PSP

Table 1 Inter-observer kappa coefficients among observers for first and second readings according to region

\begin{tabular}{lllllll} 
& Molar & & Premolar & & Anterior \\
& First reading & Second reading & First reading & Second reading & First reading & Second reading \\
Obs1-Obs2 & Obs1-Obs2 & Obs1-Obs2 & Obs1-Obs2 & Obs1-Obs2 & Obs1-Obs2 \\
\hline PSP & 0.714 & 0.72 & 0.62 & 0.693 & 0.546 & 0.43 \\
CBCT & 0.9 & 0.96 & 0.91 & 0.924 & 0.78 & 0.73 \\
pvalue & $\mathbf{p}<\mathbf{0 . 0 5}$ & $\mathbf{p}<\mathbf{0 . 0 5}$ & $\mathbf{p}<\mathbf{0 . 0 5}$ & $\mathbf{p}<\mathbf{0 . 0 5}$ & $\mathbf{p}<\mathbf{0 . 0 5}$ & $\mathbf{p}<\mathbf{0 . 0 5}$ \\
\hline
\end{tabular}


Table 2 Intra-observer agreement calculated for each observer by image type according to the regions

\begin{tabular}{|c|c|c|c|c|c|c|}
\hline & Molar & Premolar & Anterior & Molar & Premolar & Anterior \\
\hline & $\begin{array}{l}\text { Obs1 First-Second } \\
\text { reading }\end{array}$ & $\begin{array}{l}\text { Obs1 First-Second } \\
\text { reading }\end{array}$ & $\begin{array}{l}\text { Obs1 First-Second } \\
\text { reading }\end{array}$ & $\begin{array}{l}\text { Obs2 First-Second } \\
\text { reading }\end{array}$ & $\begin{array}{l}\text { Obs2 First-Second } \\
\text { reading }\end{array}$ & $\begin{array}{l}\text { Obs2 First-Second } \\
\text { reading }\end{array}$ \\
\hline PSP & 0.706 & 0.816 & 0.811 & 0.693 & 0.546 & 0.42 \\
\hline CBCT & 0.906 & 0.907 & 0.916 & 0.924 & 0.77 & 0.73 \\
\hline
\end{tabular}

2D images were the lowest Kappa values for detecting the periodontal defects esp. in the anterior region. Fleiner et al. also investigated the periodontal bone level using CBCT images. They conclude the CBCT would allow an accurate assessment of bone levels and description of infra-bony defects esp. \%100 for crater and furcation [15]. Similarly Vandenberghe et al. [14] and Misch et al. [5] also found a $\% 100$ perfect of detection rate of periodontal defects. Our results are different than their results since we didn't investigate the craters and infrabony defects. Similar to our study Braun et al. [10] created periodontal defects including dehiscence and fenestrations, the percentage of the correct diagnoses using three dimensional projections was very high (about 70 to $99 \%$ ). Our results are also similar to their result which were $78 \%$ to $95 \%$ (Table 3). Our results also confirmed that the CBCT has better diagnostic performance than PSP intra-oral images [4]. One aspect of the study that we used $0,100 \mathrm{~mm}^{3}$ isotropic voxels, the resolution in different machines may affect the detection of the periodontal defects which can be a further study.

Vasconcelos et al. [16] conducted a study to compare the periapical radiographs and CBCT. They conclude that the two methods differ when detecting the height of the alveolar bone crest but present similar views of the depth and width of bone defects. CBCT was the only method that allowed for an analysis of the buccal and lingual/ palatal surfaces and an improved visualization of the morphology of the defect which are in line with our study results. Mengel et al. [21] also investigated the periodontal defects in CBCT. They compared the dehiscences, fenestration and furcation defects which are similar to our study. CBCT in their study found more accurate and close to histopathologic investigation of the specimen. Grimard et. al. [18] compare the direct surgical measurement with $\mathrm{CBCT}$ and intraoral radiographs. They found that $\mathrm{CBCT}$ correlated strongly with the surgical measurement whereas intra-oral radiographies correlated less favorably. Walter et al. [24] studied three dimensional CBCT images for evaluating the maxillary molar furcation involvement. According to their study the furcation involvement in clinical finding that confirmed in the CBCT in only $27 \%$ of the sites, while $29 \%$ were overestimated and $44 \%$ revealed an underestimation according to CBCT analyses. The overall agreement was "moderate," with a Cohen's weighted k 0.518 (95 \% CI: 0.269-0.767).

Umetsubo et al. [25] also evaluated CBCT imaging of early incipient periodontal defect using chemical creation of the defects. They found moderate levels of intra and inter-observer agreement for detection of the defects. The variations in Kappa values for intra-and inter-observer agreement $(0.41-0.59)$. Our results can be different from the current study since our study was based on periodontal defects rather than incipient lesions. Moreover, our study revealed that the tunnel in molar furcation defects had values about 0.69 to 0.90 which are from good to very good agreement in detection of these defects.

This may due to different voxel size of the machines. Vanderberge et al. [20] in other study evaluated the detection of crater and furcation involvements. The figured out that $29 \%$ of the craters and $44 \%$ of the furcation defects were not detected and only $29 \%$ and $20 \%$ of the variables, respectively, were correctly classified. Our results were $41.20 \%$ of the dehiscence, $62.90 \%$ of the fenestrations and $82.20 \%$ of the tunnel were positive false whereas $46.80 \%$ of the dehiscence, $15.30 \%$ of the tunnel and $25.70 \%$ fenestrations were positive correct. On the CBCT images, in the same study, it was found the defects

Table 3 Evaluation according to defect types "dehiscence", "fenestration" and "tunnel"

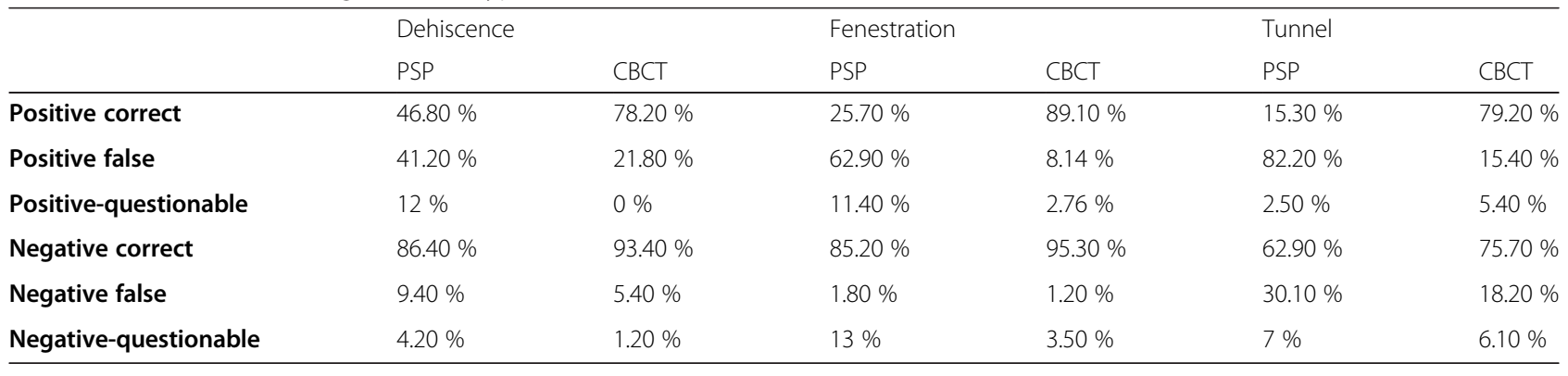


showed a $100 \%$ detectability, while $91 \%$ of the craters and $100 \%$ of the furcation involvements were correctly classified. Our results on CBCT images was between 79, $20 \%$ to $89.10 \%$ for positive correct and $75,70 \%$ to 95.30 $\%$ for negative correct for CBCT images.

The quality and diagnostic accuracy of $\mathrm{CBCT}$ images can be significantly affected by scatter and beam hardening artifacts caused by high-density adjacent structures, such as enamel, and radio-opaque materials, such as metal posts, restorations, and root filling materials [26]. Other artifacts that may obscure radiographic findings include patient movement during the scan and volume reconstruction. In this study, we used an in vitro model and teeth with artificially induced periodontal defects. To prevent artifact formation on the CBCT images, no posts or metal materials were used in the root canals.

The results of this study indicated similar results with previous studies that showed better detection rates for CBCT than the digital PSP plates for detecting the periodontal defects. In our study, we divided the regions into three as; molar, premolar and the anterior. Although no statistical significance was found between the periodontal defects individually for PSP and CBCT. The diagnostic performance in the anterior region found to be the lowest in both PSP and CBCT images. This can be due to the CBCT systems used in the present study that could focus on a FOV as $5 \times 5.5 \mathrm{~cm}$. Therefore, we were unable to radiologically analyze indirect signs of bony lesions, which can be observed as halo lesions, perilateral radiolucency, or angular resorption of the crestal bone, combined with diffuse or defined (but not corticated) borders because of considerably larger field of view. This issue can be thought to the limitation of the study.

Several studies were used natural defects $[14,23]$, chemical [27] or burs $[5,10,21]$ in order to create periodontal defects. The periodontal defect simulations were made using burs which can be a limitation of the study. The simulated model produced by burs, may not be the best method to evaluate the periodontal defects. Since, these created defects are well-defined structures or cavities but may not capture the natural architecture of the periodontal structures. Future studies should be conducted with chemical creation or with natural defects, even can be compared according to creation method of the defects.

Another limitation of the study can be the wax using as a soft tissue simulator in the study. Various materials simulating soft tissues used such as: water, wax, self-polymerizing resin, acryl, paraffin polyethylene and Plexiglas [28-33]. Water is to first used material in order to simulate soft tissue which was studies by Blake, et al. [30], and Borg et al. [31] also used water in order to simulate soft tissue to the specimen which was attached to jaw. Brand et al. [33] conducted a study in order to establish a phantom for radiation studies. They concluded that this type of phantom with soft tissue simulation can be used for radiology studies. Most of the previous studies esp. in intra-oral imaging concluded that wax can serve as reliable method for soft tissue simulation [20, 28, 33]. However, very limited information is available for soft tissue simulation in CBCT. Thus, again further studies should be conducted in order to evaluate the methods of soft tissue simulation in CBCT.

It is clear that CBCT is still not the first choice for periodontal bone support imaging [25]. Although the $\mathrm{CBCT}$ images were superior in diagnostic efficacy to conventional intraoral imaging, $\mathrm{CBCT}$ images should not necessarily replace intra-oral images. CBCT studies cause higher radiation exposures ( 4 to 20 times greater). From the standpoint of radiation risk, CBCT appears to have three to seven times the risk of a panoramic examination depending on the area examined, the degree of collimation and the acquisition software version. Thus, the decision to select an imaging modality for diagnostic purposes can be dependent for case based and should be based on the diagnostic yield expected, and in accordance with the ALARA (As Low As Reasonably Achievable) principle [34, 35].

\section{Conclusion}

In conclusion, based on our results, $\mathrm{CBCT}$ has the highest sensitivity and diagnostic accuracy for detecting various periodontal defects among the radiographic modalities examined. Further studies should be taken with different FOVs and different voxel sizes of the CBCT machines. However, from the radiation protection point of view, the diagnostic information of CBCT must improve the treatment results without such a benefit this technique should not be recommended.

\section{Abbreviations}

2D: two-dimensional; 3D: Three-dimensional; CBCT: Cone beam computed tomography; PSP: Photostimulable phosphor plates; FOV: Field of view; TIFF: Tagged image file format; TFT: Flat-panel color-active matrix thin-film transistor.

\section{Competing interests}

The authors declare that they have no competing interests.

\section{Authors' contributions}

SK, MEK and NB created the periodontal defects performed the exposures. $\mathrm{KO}$ performed the selection of the teeth and noted the results. NB and KO performed the literature search. NB and KO designed the study and helped to draft the manuscript. All authors read and approved the final manuscript.

\section{Author details}

${ }^{1}$ Faculty of Dentistry, Department of Periodontology, Ankara University, 06560, Besevler, Ankara, Turkey. ${ }^{2}$ Faculty of Dentistry, Department of Dentomaxillofacial Radiology, Ankara University, 06560 Ankara, Turkey. ${ }^{3}$ Ministry of Health, Bolu Oral and Dental Health Centre, 14000 Bolu, Turkey.

Received: 16 December 2014 Accepted: 12 May 2015

Published online: 28 May 2015

\footnotetext{
References

1. Jeffcoat MK. Current concepts in periodontal disease testing. J Am Dent Assoc. 1994;125:1071-8.
} 
2. Reddy MS. Radiographic methods in the evaluation of periodontal therapy. J Periodontol. 1992;63:1078-84.

3. Mol A. Imaging methods in periodontology. Periodontol 2000. 2004:34(Mol A):34-48.

4. Mol A, Balasundaram A. In vitro cone beam computed tomography imaging periodontal bone. Dentomaxillofac Radiol. 2008;37:319-24.

5. Misch KA, Yi ES, Sarment DP. Accuracy of cone beam computed tomography for periodontal defect measurements. J Periodontol. 2006;77:1261-6.

6. Eickholz P, Kim T-S, Benn DK, Staehle HK. Accuracy of radiographic assessments of interproximal bone loss. Oral Surg Oral Med Oral Pathol Oral Radiol Oral Endod. 1998:85:99-106.

7. Brägger U. Radiographic parameters: biological significance and clinical use. Periodontol 2000. 2005;39:73-90.

8. Alamri HM, Sadrameli M, Alshalhoob MA, Sadrameli M, Alshehri MA. Applications of $\mathrm{CBCT}$ in dental practice: a review of the literature. Gen Dent. 2012:60:390-400.

9. Benn DK. A review of the reliability of radiographic measurements in estimating alveolar bone changes. J Clin Periodontol. 1990;17:14-21.

10. Braun $X$, Ritter $L$, Jervøe-Storm PM, Frentzen M. Diagnostic accuracy of CBCT for periodontal lesions. Clin Oral Invest. 2014;18:1229-36.

11. Scarfe WC, Farman AG, Sukovic P. Clinical applications of cone-beam computed tomography in dental practice. J Can Dent Assoc. 2006:72:75-80.

12. Scarfe WC, Farman AG. What is cone-beam CT and how does it work? Dent Clin N Am. 2008:52:707-30

13. Fuhrmann RAW, Wehrbein $H$, Langen HJ, Diedrich PR. Assessment of the dentate alveolar process with high resolution computed tomography. Dentomaxillofac Radiol. 1995;24:50-4

14. Vandenberghe $B$, Jacobs $R$, Yang J. Diagnostic validity (or acuity) of 2D CCD versus $3 D$ CBCT images for assessing periodontal breakdown. Oral Surg Oral Med Oral Pathol Oral Radiol Endod. 2007;104:395-401.

15. Fleiner J, Hannig C, Schulze D, Stricker A, Jacobs R. Digital method for quantification of circumferential periodontal bone level using cone beam CT. Clin Oral Invest. 2013;17:389-96.

16. Vasconcelos KF, Evangelista KM, Rodrigues CD, Estrela C, de Sousa TO, Silva MAG. Detection of periodontal bone loss using cone beam $C T$ and intraoral radiography. Dentomaxillofac Radiol. 2012;41:64-9.

17. Ozmeric N, Kostioutchenko I, Hägler G, Frentzen M, Jervøe-Storm PM. Cone-beam computed tomography in assessment of periodontal ligament space: in vitro study on artificial tooth model. Clin Oral Invest. 2008;12:233-9.

18. Grimard BA, Hoidal MJ, Mills MP, Mellonig JT, Nummikoskim PV, Mealey BL. Comparison of Clinical, Periapical Radiograph, and Cone-BeamVolume Tomography Measurement Techniques for Assessing Bone Level Changes Following Regenerative Periodontal Therapy. J Periodontol. 2009;80:48-55.

19. Walter $C$, Weiger R, Zitzmann NU. Accuracy of three-dimensional imaging in assessing maxillary molar furcation involvement. J Clin Periodontol. 2010;37:436-41.

20. Vandenberghe $B$, Jacobs $R$, Yang J. Detection of periodontal bone loss using digital intraoral and cone beam computed tomography images: an in vitro assessment of bony and/or infrabony defects. Dentomaxillofac Radiol. 2008:37:252-60.

21. Mengel R, Candir M, Shiratori K, de-Jacoby LF. Digital Volume Tomography in the Diagnosis of Periodontal Defects: An In Vitro Study on Native Pig and Human Mandibles. J Periodontol. 2005;76:665-73.

22. Altman DG. Practical Statistics for Medical Research. London: Chapman\&Hall; 1991. p. 403-9.

23. Gomes-Filho IS, Sarmento VA, de Castro MS, da Costa NP, Cruz SS, Trindade SC, et al. Radiographic features of periodontal bone defects: evaluation of digitized images. Dentomaxillofac Radiol. 2007;36:256-62

24. Walter C, Kaner D, Berndt DC, Weiger R, Zitzmann NU. Three-dimensional imaging as a pre-operative tool in decision making for furcation surgery. J Clin Periodontol. 2009;36:250-7.

25. Umetsubo OS, Gaia BF, Costa FF, Cavalcanti MG. Detection of simulated incipient furcation involvement by CBCT: an in vitro study using pig mandibles. Braz Oral Res. 2012;26:341-7.

26. Schulze R, Heil U, Gross D, Bruellmann DD, Dranischnikow E, Schwanecke U, et al. Artefacts in CBCT: a review. Dentomaxillofac Radiol. 2011;40:265-73.

27. Da Silveira PF, Fontana MP, Oliveira HW, Vizzotto MB, Montagner F, Silveira HL, et al. CBCT-based volume of simulated root resorption - influence of FOV and voxel size. Int Endod J. 2014, Oct 5. doi: 10.1111/iej.12390.
28. Schropp L, Alyass NS, Wenzel A, Stavropoulos A. Validity of wax and acrylic as soft-tissue simulation materials used in in vitro radiographic studies. Dentomaxillofac Radiol. 2012;41:686-90.

29. Caldas MP, Moraes F, Perez M, Almeida S, Haiter-Neto F. Comparative evaluation among different materials to replace soft tissue in oral radiology studies. J Appl Oral Sci. 2010;18:264-7.

30. Blake GM, McKeeney DB, Chaya SC, Ryan PJ, Fogelman I. Dual energy x-ray absorptiometry: the effects of beam hardening on bone density measurements. Med Phys. 1992;19:4594-65.

31. Borg E, Kallqvist A, Grondahl K, Grondahl HG. Film and digital radiography for detection of simulated root resorption cavities. Oral Surg Oral Med Oral Pathol Oral Radiol Endod. 1998;86:110-4.

32. Cook JE, Cunningham JL. The assessment of fracture healing using dual x-ray absorptiometry: a feasibility study using phantoms. Phys Med Biol. 1995:40:119-36

33. Brand JW, Kuba RK, Braunreiter TC. An improved head-and neck phantom for radiation dosimetry. Oral Surg Oral Med Oral Pathol. 1989;67:338-46.

34. Angelopoulos C, Thomas SL, Hechler S, Parissis N, Hlavacek M. Comparison between digital panoramic radiography and cone-beam computed tomography for the identification of the mandibular canal as part of presurgical dental implant assessment. J Oral Maxillofac Surg. 2008;66:2130-5

35. Ludlow JB, Davies-Ludlow LE, Brooks SL. Dosimetry of two extraoral direct digital imaging devices: NewTom cone beam CT and Orthophos Plus DS panoramic unit. Dentomaxillofac Radiol. 2003;32:229-34.

\section{Submit your next manuscript to BioMed Central and take full advantage of:}

- Convenient online submission

- Thorough peer review

- No space constraints or color figure charges

- Immediate publication on acceptance

- Inclusion in PubMed, CAS, Scopus and Google Scholar

- Research which is freely available for redistribution 